\title{
Psychometric properties and feasibility of instruments used to assess awareness of deficits after acquired brain injury: a systematic review
}

Citation for published version (APA):

Smeets, S. M., Ponds, R. W. H. M., Verhey, F. R., \& van Heugten, C. M. (2012). Psychometric properties and feasibility of instruments used to assess awareness of deficits after acquired brain injury: a systematic review. Journal of Head Trauma Rehabilitation, 27(6), 433-442.

https://doi.org/10.1097/HTR.0b013e3182242f98

Document status and date:

Published: 01/01/2012

DOI:

10.1097/HTR.0b013e3182242f98

Document Version:

Publisher's PDF, also known as Version of record

Document license:

Taverne

Please check the document version of this publication:

- A submitted manuscript is the version of the article upon submission and before peer-review. There can be important differences between the submitted version and the official published version of record.

People interested in the research are advised to contact the author for the final version of the publication, or visit the DOI to the publisher's website.

- The final author version and the galley proof are versions of the publication after peer review.

- The final published version features the final layout of the paper including the volume, issue and page numbers.

Link to publication

\footnotetext{
General rights rights.

- You may freely distribute the URL identifying the publication in the public portal. please follow below link for the End User Agreement:

www.umlib.nl/taverne-license

Take down policy

If you believe that this document breaches copyright please contact us at:

repository@maastrichtuniversity.nl

providing details and we will investigate your claim.
}

Copyright and moral rights for the publications made accessible in the public portal are retained by the authors and/or other copyright owners and it is a condition of accessing publications that users recognise and abide by the legal requirements associated with these

- Users may download and print one copy of any publication from the public portal for the purpose of private study or research.

- You may not further distribute the material or use it for any profit-making activity or commercial gain

If the publication is distributed under the terms of Article $25 \mathrm{fa}$ of the Dutch Copyright Act, indicated by the "Taverne" license above, 


\title{
Psychometric Properties and Feasibility of Instruments Used to Assess
}

\section{Awareness of Deficits After Acquired Brain Injury: A Systematic Review}

\author{
Sanne M. J. Smeets, MSc; Rudolf W. H. M. Ponds, PhD; Frans R. Verhey, PhD, MD; \\ Caroline M. van Heugten, PhD
}

\begin{abstract}
Background: Unawareness of deficits after acquired brain injury (ABI) is often reported in the clinic. Several methods have been developed to measure a patient's awareness of deficits after ABI; however, no criterion standard currently exists to measure this phenomenon. Objective: To review all instruments for measuring awareness of deficits and evaluate their psychometric and conceptual properties as well as their feasibility. Methods: Systematic literature search for available awareness measurement instruments used in experimental ABI studies. Instruments were divided into the following 4 assessment methods: clinician ratings, structured interviews, performance-based discrepancy, and self-other rating discrepancy methods. The quality of the instruments was evaluated. Results: The literature search identified 39 instruments and 8 of these were selected. The following 3 instruments stood out in terms of quality: Self-Awareness of Deficits Interview, Patient Competency Rating Scale, and Awareness Questionnaire. Conclusion: Although these quantitative instruments are useful tools in research, they have limited utility in the clinic because they only measure intellectual awareness. Therefore, in addition to these instruments, qualitative tools should also be used to gain a complete view of a patient's awareness problem. Key words: aweareness, brain injuries, literature revierw, measurement instruments
\end{abstract}

$\mathrm{D}$ IMINISHED AWARENESS of deficits after acquired brain injury (ABI) is a well-known clinical problem. Within the ABI literature, impaired awareness of deficits refers to reduced ability to appraise one's strengths and weaknesses and the implications for daily life activities at present and in the future. ${ }^{1,2}$ The incidence of this phenomenon has been reported to range from $30 \%$ to $97 \%$ depending on the instrument used, the severity of injury, andthe time since injury. ${ }^{1,3-9}$ Patients often lack awareness of their cog-

Author Affiliations: School for Mental Health and Neuroscience (MHeNS), Department of Psychiatry and Neuropsychology (Ms Smeets and Drs Ponds, Verbey, and Heugten) and Department of Neuropsychology and Psychopharmacology, Faculty of Psychology and Neuroscience (Dr van Heugten), Maastricht University, The Netherlands; Mondriaan, Department Psy Q, Maastricht, The Netherlands (Dr Ponds); and Department of Psychiatry and Psychology, Maastricht University Medical Center (MUMC)/Alzheimer Center Limburg, Maastricht, The Netherlands (Drs Ponds and Verhey).

These authors declare no conflicts of interest.

Corresponding Author: Caroline van Heugten, PhD, School for Mental Health and Neuroscience (MHeNS), Department of Psychiatry and Neuropsychology, Maastricht University, PO Box 616, 6200 MD Maastricht, The Netherlands (c.vanheugten@maastrichtuniversity.nl).

DOI: $10.1097 /$ HTR.0b013e3182242f98 nitive deficits, disturbing behavior, and impaired interpersonal skills as well as the effects of these deficits on others. ${ }^{10}$ Currently, there is no clinical consensus regarding the pathogenesis underlying this lack of awareness, but frontal lobe dysfunction has often been linked to this phenomenon. ${ }^{10-12}$

The failure to recognize one's own deficits can be very disabling, as it is associated with an unfavorable shortand long-term employment outcome $e^{13,14}$ and can have consequences for treatment. Patients who have limited appreciation of their impairments can have decreased motivation to participate in treatment, ${ }^{15}$ while those who are more aware of their deficits may exhibit better treatment adherence and performance. ${ }^{16,17}$

In the clinic, it is important to gauge a patient's level of awareness of deficits as this determines, in part, an appropriate intervention strategy. According to Crosson et $\mathrm{al}^{18}$ a patient's awareness of deficits after ABI can be divided into 3 levels. At the lowest level, intellectual awareness, the patient is able to understand to some degree that a specific function is impaired as compared with before the injury. At the second level, emergent awareness, the patient can recognize a problem when it is actually arising. The third and highest level is anticipatory 
awareness, which indicates that a patient is able to anticipate a problem. With regard to intervention techniques, external compensation is most appropriate for a patient with no intellectual awareness, whereas anticipatory compensation strategies can only be taught to patients with a certain level of anticipatory awareness. ${ }^{19}$

This model is known as the pyramid model of awareness, formulated by Crosson and colleagues on the basis of their work with ABI patients. ${ }^{18}$ In a preliminary study, Abreu et $\mathrm{al}^{20}$ found no evidence supporting the hierarchical structure of the model. Other researchers criticize its hierarchical and interdependent levels ${ }^{21}$ and propose other more dynamic frameworks to describe awareness that elaborate on the pyramid model. ${ }^{11,21}$ One of these frameworks is a broad preliminary biospsychosocial model proposed by Ownsworth et al. ${ }^{11}$ It describes relevant factors related to awareness on 3 levels (biological, psychological, and social) influenced by the subjective experience of self. ${ }^{11}$ The broad and interactive nature of this model may better reflect the current view on awareness of deficits than does the pyramid model. However, both models need further validation. In this review, the pyramid model is seen as a useful guideline for clinicians, who often use it because of its intuitive sense and applicability. ${ }^{11}$

In research studies, it is also relevant to account for awareness of deficits. For instance, the results of an intervention study can be affected by a patient's lack of awareness of deficits. Furthermore, patients with diminished awareness of deficits might not complete questionnaires in a reliable fashion. Therefore, it is important to objectively detect impaired awareness of deficits in both clinical and research settings. Several assessment techniques have been developed to measure the awareness of deficits after ABI, but so far, no criterion standard has been defined. Furthermore, studies that attempted to measure awareness of deficits differ in several aspects. Some are group studies, ${ }^{9}$ whereas others use a single case design.22 Other studies use a single item from existing questionnaires to assess awareness of deficits, ${ }^{23}$ which is in contrast to those that use extensive questionnaires specifically designed for this purpose. ${ }^{24} \mathrm{An}$ other noticeable difference is that some studies use a domain-specific awareness measurement (eg, asses only awareness of memory deficits ${ }^{25}$ ), whereas others assess awareness in multiple domains. ${ }^{24}$ Some reviews give a descriptive overview of the awareness of deficits instruments used in these studies, ${ }^{1,26,27}$ but information about psychometric qualities is mostly lacking. Consequently, recommendations for the optimal awareness instrument to be used in ABI patients are problematic.

Therefore, the aim of this systematic review was to generate an overview of the measurement instruments currently available and to evaluate their psychometric quality, their conceptualization of the construct of awareness, and their feasibility. In addition, we attempt to answer the following 4 research questions: (1) Which measurement instruments have been used in empirical studies investigating impaired awareness of deficits after ABI? (2) what is known about their psychometric, conceptual and feasibility properties? (3) which instrument is best suited to identify and research awareness of deficits in ABI patients given its psychometric properties, conceptualization and feasibility? and (4) which instrument can be recommended for use in clinical practice?

\section{METHODS}

\section{Selection of articles and measurement instruments}

Instruments were selected by means of a systematic computerized literature search using PubMed (1953 to January, 2010), PsycInfo (1887 to January, 2010) and EMBASE (1989 to January, 2010). Each search consisted of the following 2 principle components: $A B I$ and awareness. Details of the search terms are shown in Appendix 1.

Articles were selected if they described an empirical study assessing awareness of deficits after $A B I$ in adults (aged 18 years or older) and if they were written in English, Dutch, French, or German. Case reports and review articles were excluded. Furthermore, instruments were not selected if there was only 1 publication in which the instrument was used, if they assessed awareness in 1 specific domain (such as memory), used a subscale or 1 item of a questionnaire, or were initially designed to measure a construct other than awareness.

The first author (S.S.) executed the selection procedure. In case of doubt, the second (R.P.) and fourth (C.vH.) authors independently judged the specific article. The article in question was included if it was selected by one of the authors.

\section{Classification of measurements}

The relevant instruments from the selected articles were divided into 4 methods on the basis of previous reviews. ${ }^{1,26,27}$ First, in the clinician ratings method, a clinician rates the awareness of a subject on the basis of clinical judgment. Structured intervieres are designed to acquire quantitative as well as qualitative information about the degree of awareness of deficits and are completed by a clinician. The performance-based discrepancy method assumes that awareness of deficits can be derived from the difference between the patients' opinion about their functioning and an objective standard. In this case, the patient's performance on an objective (neuropsychological) test is compared with their prediction of their performance on the test. Fourth, in the self-other rating discrepancy method, the objective standard is a person who knows the patient well. Patients 
and significant others usually complete questionnaires that are about competencies of daily functioning.

\section{Evaluation of the psychometric properties}

After the selection of instruments, a second search was conducted to identify articles that provided information about the psychometric properties of the selected instruments. Again, a systematic computerized literature search was conducted using PubMed (1953 to April, 2010), PsycInfo (1887 to April, 2010), and EMBASE (1989 to April, 2010). Each search included the name or abbreviation of the selected awareness instrument and terms indicating the psychometric properties (eg, reliability and validity). Details of the second search are shown in Appendix 2. If no or few articles were found, additional psychometric information for an instrument was acquired from articles from the first search.

The psychometric properties were evaluated following the criteria used in the systematic review of Visser-Meily et $\mathrm{al}^{28}$ The internal consistency, examined with Cronbach $\alpha$ coefficient, was considered good if the alpha value was $>0.8$, moderate if alpha was between 0.7 and 0.8 , acceptable if alpha was between 0.6 and 0.7 , and poor if alpha was $<0.6$. Test-retest reliability was considered good if the correlation coefficient from separate administrations of a test was $>0.8$, moderate if scores were between 0.7 and 0.8 , and insufficient if scores were $<0.7$. Interrater reliability was evaluated as good if the intraclass correlation (ICC) or Pearson correlation coefficient between raters was $>0.8$, moderate if scores were between 0.7 and 0.8 , and insufficient if scores were $<0.7$. The convergent validity was considered good if the correlation coefficient between 2 awareness measures was $>0.6$, moderate if scores were between 0.3 and 0.6, and poor if the coefficients were lower than 0.3. Construct validity was considered positive if the structure of the measurement instrument was confirmed by factor or principal components analysis, and it was considered negative if not. Responsiveness (ability to measure change) was rated as positive if changes in awareness as measured by the instrument in follow-up studies were significant $(P<.05$ or effect size $>0.4)$ and negative if changes were non-significant $(P>.05$ or effect size $<0.4)$.

\section{Conceptualization}

The conceptual strength of these instruments was examined with regard to 4 aspects on the basis of the definitions and conceptual framework of awareness within the ABI literature. ${ }^{1,2,29}$ First, the definition of awareness should be incorporated into the instrument. Second, an instrument should assess the degree of awareness, because awareness is not an all-or-nothing phenomenon. ${ }^{30}$ Third, instruments need to measure multiple objects of awareness (ie, assess awareness across various domains). ${ }^{11,27,29,30}$ Fourth, the instrument should have separate subscales to evaluate awareness within each domain.

\section{Feasibility}

The feasibility of each instrument was evaluated on the basis of the following aspects: availability (ie, an easily obtainable instrument), the duration of assessment, and the availability of the instrument in different languages. This aspect was based on the versions of the instruments used in the published studies.

\section{RESULTS}

The literature search identified 1626 articles that were evaluated according to the above inclusion criteria. Two potentially relevant articles were not accessible despite numerous efforts to obtain them and were not included in this review. ${ }^{31,32}$ Eventually, 142 articles met the specified inclusion criteria and were used for evaluation (Figure 1).

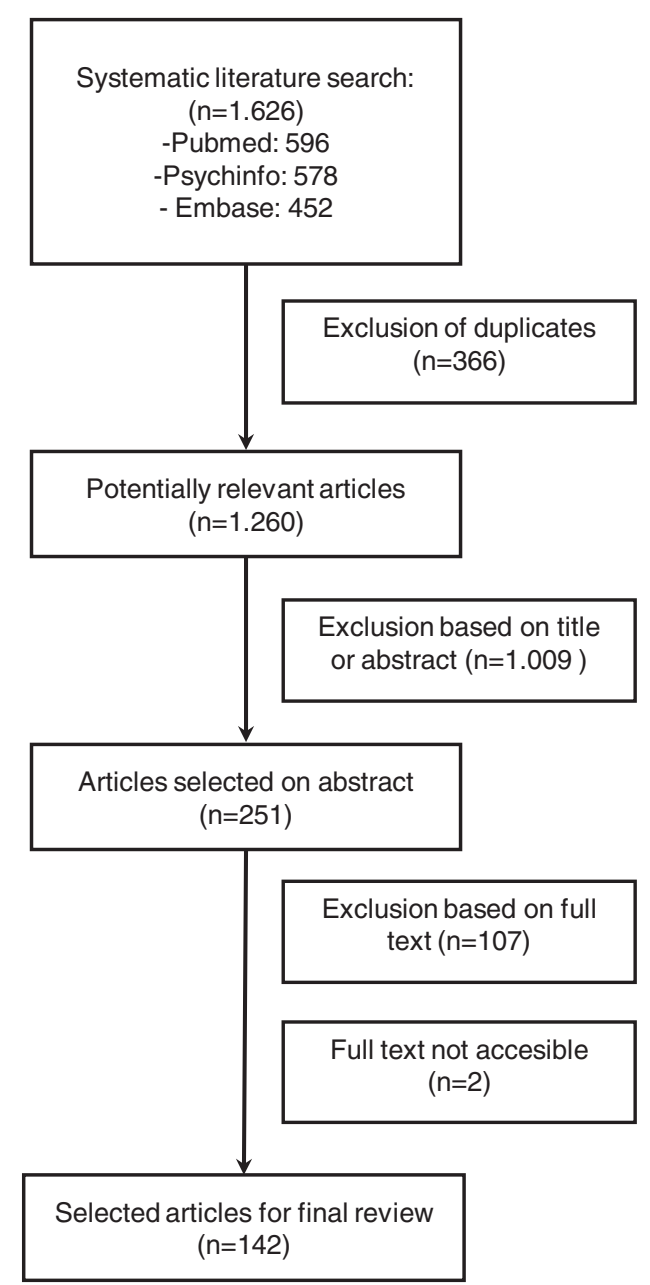

Figure 1. Flowchart of the selection of articles.

www.headtraumarehab.com 
TABLE 1 Excluded measurement instruments

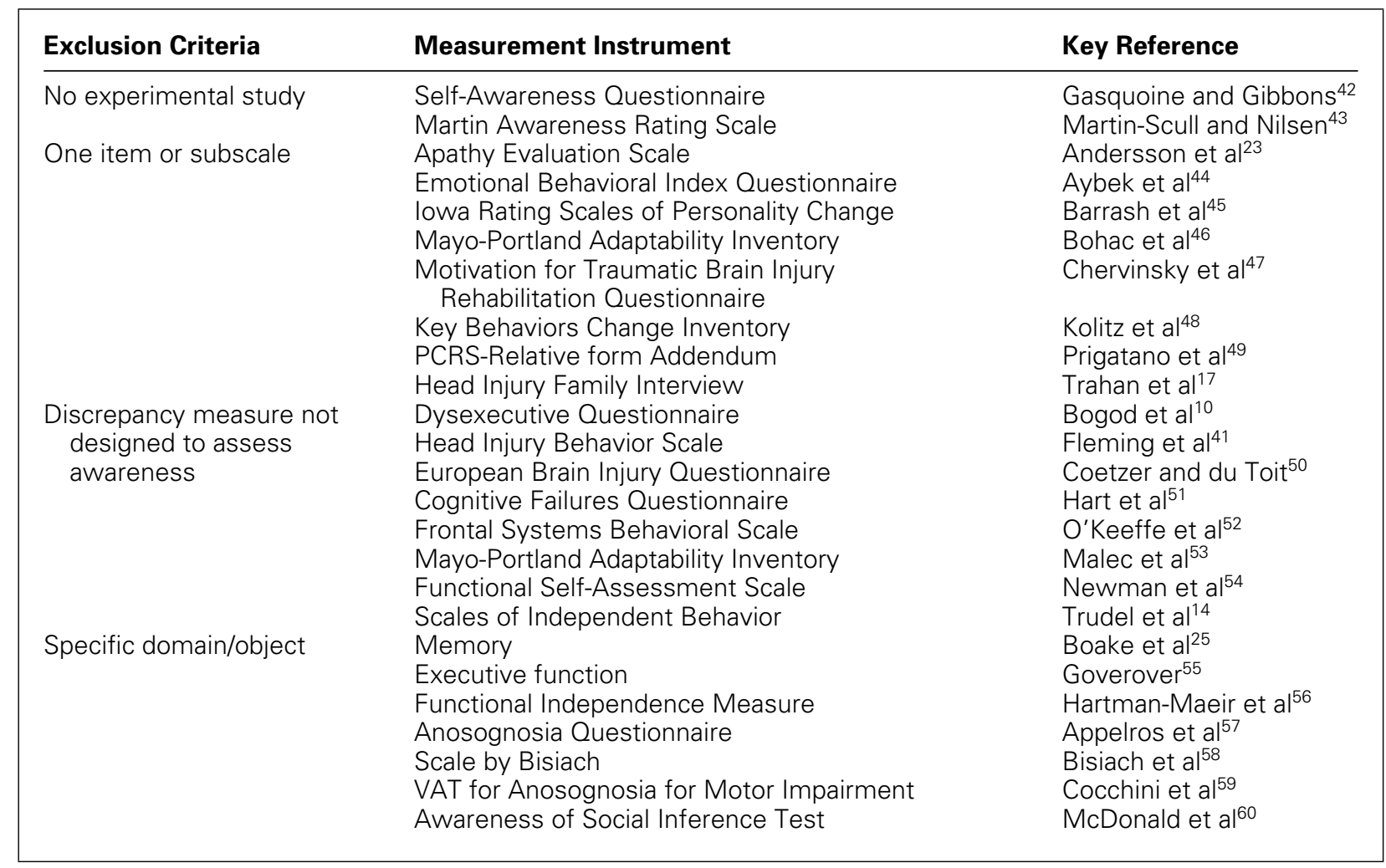

Abbreviations: PCRS, patient competency rating scale; VAT, visual analogue test.

Among these published studies, 39 different measurement instruments were used, but 25 did not meet the inclusion criteria and were subsequently excluded. The instruments and reasons for exclusion can be found in Table 1.

The following instruments were not evaluated because they were only used once in an ABI sample: the Denial of Illness Scale of Starkstein et al, ${ }^{33}$ the Denial of Illness Scale of Narushima et al, ${ }^{34}$ the Daily Tasks Performance method, ${ }^{20}$ the modified Competency Rating Scale, ${ }^{35}$ the Questionnaire of Malia, ${ }^{36}$ and the Awareness of Deficits Questionnaire. ${ }^{8}$ These exclusions resulted in 8 measurement instruments that were reviewed and are presented in Table 2.

\section{Psychometric properties of the instruments}

In Table 3, a summary of the psychometric properties of these 8 instruments is shown. The values presented are overall values of the individual instruments. Some measures had information about the internal consistency of separate subscales, but to clarify the table, this information has not been included (values can be acquired by contacting the corresponding author).

In addition, the Patient Competency Rating Scale (PCRS) and the Awareness Questionnaire (AQ) had different forms with separate reliability values. Therefore, they are represented in Table 3 with the patient's form, significant other's form, and clinician's form. Furthermore, the degree of awareness of these scales was derived from the discrepancy between the patients' score on the scale and the significant other's or clinician's score. Thus, for determining the convergent validity this score was used.

The results indicated that many instruments lacked psychometric information. However, the quality of the Self-Awareness of Deficits Interview (SADI), PCRS and AQ has been studied more extensively. The SADI had good reliability, but little validity information was available. The PCRS had good reliability, validity, and responsiveness, but reliability information was not available for all PCRS forms. The AQ had good internal consistency and validity, but lacked interrater and testretest reliability information.

\section{Conceptualization and feasibility}

Evaluation of the conceptualization of awareness of deficits among the measurement instruments revealed that the majority of these instruments measured a degree of awareness. Some authors who use clinical judgment as an instrument allowed for the possibility of dichotomous answers (ie, present/absent). Concerning the definition of awareness instruments, all measures 
TABLE 2 Included awareness instruments

\begin{tabular}{|c|c|c|c|c|c|}
\hline Method & Instruments & $\begin{array}{l}\text { Times } \\
\text { Used }\end{array}$ & Key Feature & Example Question & $\begin{array}{c}\text { Key } \\
\text { Reference }\end{array}$ \\
\hline \multirow[t]{2}{*}{ Clinician ratings } & $\begin{array}{l}\text { Clinical } \\
\text { Judgment }\end{array}$ & 8 & $\begin{array}{l}\text { Professional } \\
\text { knowledge }\end{array}$ & $\begin{array}{l}\text { Patient verbalizes only } \\
\text { partial awareness in } \\
\text { response to direct } \\
\text { query, but may } \\
\text { deny problems at } \\
\text { another point. }\end{array}$ & $\begin{array}{l}\text { Langer and } \\
\text { Samuels }\end{array}$ \\
\hline & CRS & 3 & $\begin{array}{l}\text { Distinction impaired } \\
\text { self-awareness } \\
\text { and denial }\end{array}$ & $\begin{array}{l}\text { Patient does not } \\
\text { appear to recognize } \\
\text { the interpersonal or } \\
\text { social impact of an } \\
\text { impairment. }\end{array}$ & $\begin{array}{l}\text { Prigatano and } \\
\text { Klonoff }{ }^{22}\end{array}$ \\
\hline \multirow[t]{2}{*}{$\begin{array}{l}\text { Structured } \\
\text { interviews }\end{array}$} & SADI & 18 & $\begin{array}{l}\text { Awareness of, and } \\
\text { implications of } \\
\text { disabilities }\end{array}$ & $\begin{array}{l}\text { "Are you any different } \\
\text { now compared to } \\
\text { what you were like } \\
\text { before your } \\
\text { accident?" }\end{array}$ & Fleming et al ${ }^{1}$ \\
\hline & SRSI & 8 & $\begin{array}{l}\text { Meta-cognitive } \\
\text { skills in everyday } \\
\text { living }\end{array}$ & $\begin{array}{l}\text { "Can you tell me how } \\
\text { you know that you } \\
\text { experience (main } \\
\text { difficulty); that is, } \\
\text { what do you notice } \\
\text { about yourself?" }\end{array}$ & $\begin{array}{l}\text { Ownsworth } \\
\text { et al }{ }^{63}\end{array}$ \\
\hline \multirow[t]{2}{*}{$\begin{array}{l}\text { Performance- } \\
\text { based } \\
\text { discrepancy }\end{array}$} & $\begin{array}{l}\text { NPA vs } \\
\text { prediction }\end{array}$ & 8 & $\begin{array}{l}\text { Patients' opinion } \\
\text { about cognitive } \\
\text { abilities vs. neu- } \\
\text { ropsychological } \\
\text { test profile }\end{array}$ & $\begin{array}{l}\text { "Are you having } \\
\text { trouble with your } \\
\text { memory?" }\end{array}$ & $\begin{array}{l}\text { Anderson } \\
\text { and } \\
\text { Tranel } 64\end{array}$ \\
\hline & AAD & 2 & $\begin{array}{l}\text { Observational } \\
\text { assessment of } \\
\text { motor and } \\
\text { process aspects } \\
\text { of daily activities }\end{array}$ & $\begin{array}{l}\text { "Can you describe } \\
\text { whether you } \\
\text { experienced any } \\
\text { specific difficulties } \\
\text { during the } \\
\text { performance?" }\end{array}$ & Tham et a ${ }^{65}$ \\
\hline \multirow[t]{2}{*}{$\begin{array}{l}\text { Self-other rating } \\
\text { discrepancy }\end{array}$} & PCRS & 33 & $\begin{array}{l}\text { Awareness of } \\
\text { abilities in four } \\
\text { areas of } \\
\text { functioning }\end{array}$ & $\begin{array}{l}\text { How much of a } \\
\text { problem do I have in } \\
\text { preparing my own } \\
\text { meals? }\end{array}$ & $\begin{array}{l}\text { Prigatano } \\
\text { et al }{ }^{66}\end{array}$ \\
\hline & $\mathrm{AQ}$ & 21 & $\begin{array}{l}\text { Current vs. before } \\
\text { injury functioning } \\
\text { of daily activities }\end{array}$ & $\begin{array}{l}\text { How good is your } \\
\text { ability to live } \\
\text { independently now } \\
\text { as compared to } \\
\text { before your injury? }\end{array}$ & Sherer et al ${ }^{24}$ \\
\hline
\end{tabular}

Abbreviations: AAD, Assessment of Awareness of Disability; AQ, Awareness Questionnaire; CRS, Clinicians Rating Scale for Evaluating Impaired Self-Awareness and Denial of Disability after Brain Injury; NPA vs prediction, neuropsychological assessment vs patients' prediction; PCRS, Patient Competency Rating Scale; SADI, Self-Awareness of Deficit Interview; SRSI, Self-Regulation Skills Interview.;

incorporated the ability of the patient to appraise his or her strengths and weaknesses. However, only 4 addressed the implications of the patient's deficits now and in the future. With regard to feasibility, all instruments were available in English. Spanish and Hebrew versions of the PCRS were also available. In Table 4, the remaining conceptual and feasibility properties of the awareness instruments are presented.

These results showed that the instruments mainly differed conceptually. In the questionnaires (PCRS, AQ, and the Clinicians Rating Scale for Evaluating Impaired Self-Awareness and Denial of Disability After Brain Injury) different domains are included. The interview techniques do not incorporate various domains, but leave open the choice to address a certain deficit. Clinicians can do multiple assessments with these instruments to measure various domains. In that sense these instruments are not restricted to 1 domain. Regarding the interpretation of awareness in different domains, only in the AQ is the possibility to interpret awareness in 
TABLE 3 Psychometric aspects of the awareness measurement instruments ${ }^{a}$

\begin{tabular}{|c|c|c|c|c|c|c|}
\hline & $\begin{array}{l}\text { Construct } \\
\text { Validity }\end{array}$ & $\begin{array}{l}\text { Convergent } \\
\text { Validity }\end{array}$ & $\begin{array}{c}\text { Internal } \\
\text { Consistency }\end{array}$ & $\begin{array}{l}\text { Interrater } \\
\text { Reliability }\end{array}$ & $\begin{array}{c}\text { Test- } \\
\text { retest } \\
\text { Reliability }\end{array}$ & Responsiveness \\
\hline 1. Clinical judgment & na & \pm & + & + & - & $?$ \\
\hline 2. CRS & $?$ & $?$ & $?$ & + & $?$ & + \\
\hline 3. SADI & $?$ & \pm & $?$ & + & + & + \\
\hline 4. SRSI & + & - & $?$ & + & - & - \\
\hline 5. NPA vs. prediction & $?$ & \pm & $?$ & + & $?$ & $?$ \\
\hline 6. AAD & $?$ & $?$ & $?$ & $?$ & $?$ & + \\
\hline 7. PCRS Patient's form & + & na & + & na & + & + \\
\hline PCRS Relative's form & + & na & + & + & $?$ & $?$ \\
\hline PCRS Clinician's form & + & na & + & + & $?$ & $?$ \\
\hline PCRS Discrepancy ${ }^{a}$ & na & \pm & na & na & na & + \\
\hline 8. AQ Patient's form & + & na & + & $?$ & $?$ & $?$ \\
\hline AQ Relative's form & + & na & + & $?$ & $?$ & + \\
\hline AO Clinician's form & $?$ & na & $?$ & $?$ & $?$ & $?$ \\
\hline AO discrepancy & na & + & na & na & na & - \\
\hline
\end{tabular}

Abbreviations: AAD, Assessment of Awareness of Disability; AQ, Awareness Questionnaire; CRS, Clinicians Rating Scale for Evaluating Impaired Self-Awareness and Denial of Disability after Brain Injury; NPA vs prediction, neuropsychological assessment vs patients' prediction; PCRS, Patient Competency Rating Scale; SADI, Self-Awareness of Deficit Interview; SRSI, Self-Regulation Skills Interview. a + sufficient; \pm moderate; - insufficient; ? unknown/unclear; na not applicable.

${ }^{b}$ Discrepancy scores: patient form vs relative form/clinician form.

TABLE 4 Conceptualization and feasibility ${ }^{a}$

\begin{tabular}{|c|c|c|c|c|c|}
\hline & \multicolumn{3}{|c|}{ Conceptualization } & \multicolumn{2}{|c|}{ Feasibility } \\
\hline & Implications $^{\mathbf{b}}$ & Domains & Subscales & Availability & Duration \\
\hline Clinical judgment & Yes/no & Yes/no & Yes/no & Author & $5 \mathrm{~min}$ \\
\hline CRS & Yes & Yes & No & Article & $10 \mathrm{~min}$ \\
\hline SADI & Yes & No & No & Article & $20-30 \mathrm{~min}$ \\
\hline SRSI & Yes & No & No & Article & $20 \mathrm{~min}$ \\
\hline NPA vs prediction & No & Yes/no & Yes & Publisher & $10-60 \min ^{\circ}$ \\
\hline AAD & No & No & No & Article & $45 \mathrm{~min}$ \\
\hline PCRS & No & Yes & No & Web site & $15 \min$ \\
\hline $\mathrm{AQ}$ & No & Yes & Yes & Web site & $10 \mathrm{~min}$ \\
\hline
\end{tabular}

Abbreviations: AAD, Assessment of Awareness of Disability; AQ, Awareness Questionnaire; CRS, Clinicians Rating Scale for Evaluating Impaired Self-Awareness and Denial of Disability after Brain Injury; NPA vs prediction, neuropsychological assessment vs patients' prediction; PCRS, Patient Competency Rating Scale; SADI, Self-Awareness of Deficit Interview; SRSI, Self-Regulation Skills Interview. aYes, incorporated in the instrument; No, not incorporated in the instrument; Yes/no, depends on the technique used.

b Instrument assesses insight into implications of the patient's deficits on life now and in the future.

${ }^{\mathrm{c}}$ Duration of assessment depends on the amount of neuropsychological tests administered.

separate domains incorporated in the questionnaire. Most instruments were freely available, but they did vary in their assessment method and administration time.

\section{DISCUSSION}

The purpose of this systematic review was to provide an overview of measurement instruments that assessed an ABI patient's awareness of deficits and the psychometric properties as well as the conceptualization and feasibility of these instruments. A literature search identified 39 different instruments but only 8 met the inclusion criteria and were used for further evaluation. After evaluation of the psychometric properties, the following 3 instruments stood out: the SADI, PCRS, and AQ. For these instruments, most psychometric information was available, and they possessed the best psychometric properties.

The final choice of instrument to be used depends on what and how one wants to measure. Therefore, a closer look into the conceptualization and feasibility is required. Concerning the conceptualization, the PCRS and AQ differ slightly. Both instruments assess degrees of awareness in various domains but only the AQ allows separate interpretation of these domains. Another 
conceptual difference was that the PCRS asked about the patient's competencies in the present time, whereas the AQ asked the respondent to compare current functioning with the way it was before the brain injury. The SADI conceptually differentiated itself from the PCRS and AQ by including questions about the implications of the deficits for life at present and in the future. However, this instrument could not assess different domains.

Regarding the feasibility of the SADI, PCRS, and AQ, they differed in their administration method (ie, questionnaire or interview style). All instruments were easily accessible, but the SADI took longer to administer (20-30 minutes). Although all instruments were feasible, depending on the resources available, one might choose the AQ or PCRS because these are self-report measures instead of clinician-rated interviews and they take less time to complete (10-15 minutes).

This review demonstrates that there is a proliferation of instruments assessing awareness of deficits after ABI. Many researchers develop their own means to assess a patient's awareness and consequently only a few assessment techniques have been used frequently. It appeared that the psychometric properties were unknown for 6 of the 8 instruments. Thus, even though these measurement instruments appeared to have good face validity, at this time, no judgment about their psychometric quality can be made. Accordingly, further research into these instruments is needed.

An important issue is the validity of the informant within the self-other ratings method. Researchers often have questioned the accuracy of relatives' judgments about a patient's functioning. ${ }^{26,27}$ It has been observed that relatives' judgments can be influenced by their own experience of depression, anxiety, or burden. ${ }^{37,38}$ Sherer et $\mathrm{al}^{39}$ found that the ratings of clinicians and significant others for the PCRS and AQ were moderately correlated. This indicates that the ratings of the patient's relatives differ only slightly from the clinician's ratings, which may be more objective. Nevertheless, more research is needed to explore this matter.

With regard to the levels of awareness described by the pyramid model, questionnaires and structured interviews only assess intellectual awareness. ${ }^{1}$ Their quantitative nature is suitable to answer specific research questions concerning prognosis and treatment success. ${ }^{1}$ In the clinic, these instruments are useful for measuring intellectual awareness; however, observations by trained professionals are needed to assess emergent and anticipatory awareness. ${ }^{19}$ Reference books ${ }^{40}$ provide information that could be a starting point for clinicians in determining the level of awareness of a patient in addition to the methods discussed in this review. Also the Assessment of Awareness of Disability is an example of a more qualitative observational approach to assess awareness. This measurement is used in combination with the
Assessment of Motor and Process Skills. Although this approach seems valid, this review found no evidence to support this. More research is needed into assessment techniques that can capture emergent and anticipatory awareness concepts.

Because of the variability of instruments used to assess awareness of deficits and their differences in quality, a criterion standard to measure awareness would be of great value. The psychometric analysis only offers limited support for current tools and therefore no instrument reviewed in this article can be considered a criterion standard. We believe that the best strategy to achieve a criterion standard would be to improve or adapt existing instruments instead of developing yet other instruments to measure awareness. For this purpose, we think that the SADI, PCRS, and AQ are the primary candidates. A criterion standard should have high quality and be applicable in both research and clinical settings.

This review was designed to capture all measurement instruments published in empirical studies. Although the search was as broad as possible, a few articles may have been missed. The review was also designed in a way that it captured measurements for $\mathrm{ABI}$ and not solely for traumatic brain injury or stroke. The scales indeed have been used in patients with different ABI etiologies. Yet, it appears that much of the psychometric research of the measurements evaluated in this review is done in patients with traumatic brain injury. However, we assume that the instruments can also be used in patients with, for example, stroke or hypoxia. According to the criteria used in this review, instruments should assess multiple domains and therefore should be able to overcome differences in deficits among ABI etiologies. Nevertheless, these assumptions need to be validated in further research.

Furthermore, as a consequence of our strict exclusion criteria, we might have excluded potentially good instruments. For example, the "off-label" questionnaires (ie, questionnaires not designed to measure awareness but used as discrepancy measures) to assess awareness were excluded for evaluation (eg, Dysexecutive Questionnaire ${ }^{10}$ or Head Injury Behavior Scale ${ }^{41}$ ). However, these tools may still be useful in assessing the awareness of deficits of ABI patients. For example, the Dysexecutive Questionnaire correlated moderately with the SADI. ${ }^{10}$ Also measurements that focus on 1 domain were excluded. These instruments might be good and useful as well, but it was chosen to only evaluate instruments that assess awareness in a broader sense, for example, over multiple domains because these reflect the awareness of deficit concept better.

To conclude, a variety of instruments are available to measure a patient's awareness of deficits after ABI. Most of these tools have limited support and need more

www.headtraumarehab.com 
research to gain insight into their quality. This review revealed that the SADI, AQ, and PCRS are useful tools for measuring awareness and have acceptable psychometric and conceptual properties as well as feasibility. Although additional research into the quality and conceptualization of these instruments is required, their quantitative nature makes them suitable for use in research, because a patient's awareness of their deficits can be an important confounding factor in research settings. Moreover, in the clinic, qualitative tools are needed to determine the level of awareness of deficits among ABI patients and to guide development of effective treatment plans.

\section{REFERENCES}

1. Fleming J, Strong J, Ashton R. Self-awareness of deficits in adults with traumatic brain injury: how best to measure? Brain Inj. 1996;10:1-16.

2. Prigatano GP, Schacter DL. Introduction. In: Prigatano GP, Schacter DL, eds. Awareness of Deficit After Brain Injury: Clinical and Theoretical Issues. New York City, NY: Oxford University Press, Inc; 1991.

3. Fleming J, Winnington HT, McGillivray AJ, Tatarevic BA, Ownsworth TL. The development of self-awareness and relationship to emotional functioning during early community reintegration after traumatic brain injury. Brain Impair. 2006;7:83-94.

4. Hoofien D, Gilboa A, Vakil E, Barak O. Unawareness of cognitive deficits and daily functioning among persons with traumatic brain injuries. J Clin Exp Neuropsych. 2004;26:278-290.

5. McBrinn J, Wilson FC, Caldwell $S$ et al. Emotional distress and awareness following acquired brain injury: an exploratory analysis. Brain Inj. 2008;22:765-772.

6. Noe E, Ferri J, Caballero MC, Villodre R, Sanchez A, Chirivella J. Self-awareness after acquired brain injury: predictors and rehabilitation. J Neurol. 2005;252:168-175.

7. Oppenheim-Gluckman H, Fayol P, DeCollasson P, Dumond JJ, Azouvi P. The psychopathology of the unawareness of cognitive impairments and behavioral limitations in traumatic brain-injured patients. Ann Readapt Med Phys. 2003;46:41-48.

8. Port A, Willmott C, Charlton J. Self-awareness following traumatic brain injury and implications for rehabilitation. Brain Inj. 2002;16:277-289.

9. Prigatano GP, Altman IM. Impaired awareness of behavioral limitations after traumatic brain injury. Arch Phys Med Rebabil. 1990;71:1058-1064.

10. Bogod NM, Mateer CA, Macdonald CA SWS. Self-awareness after traumatic brain injury: a comparison of measures and their relationship to executive functions. JInt Neuropsychol Soc. 2003;9:450458.

11. Ownsworth T, Clare L, Morris R. An integrated biopsychosocial approach to understanding awareness deficits in Alzheimer's disease and brain injury. Neuropsychol Rehabil. 2006;16(4):415-483.

12. Stuss DT, Levine B. Adult clinical neuropsychology: lessons from studies of the frontal lobes. Annu Rev Psychol. 2002;53:401-433.

13. Sherer M, Bergloff P, Levin E, High Jr WM, Oden KE, Nick TG. Impaired awareness and employment outcome after traumatic brain injury. J Head Trauma Rebabil. 1998;13(5):52-61.

14. Trudel TM, Tryon WW, Purdum CM. Awareness of disability and long-term outcome after traumatic brain injury. Rehabil Psychol. 1998;43:267-281.

15. Flashman LA, McAllister TW. Lack of awareness and its impact in traumatic brain injury. NeuroRehabilitation. 2002;17:285-296.

16. Lam CS, McMahon BT, Priddy DA, Gehred-Schultz A. Deficit awareness and treatment performance among traumatic head injury adults. Brain Inj. 1988;2:235-242.

17. Trahan E, Pépin M, Hopps S. Impaired awareness of deficits and treatment adherence among people with traumatic brain injury or spinal cord injury. J Head Trauma Rebabil. 2006;21: 226-235.
18. Crosson B, Barco PP, Velozo CA et al. Awareness and compensation in postacute head injury rehabilitation.J Head Trauma Rehabil. 1989;4:46-54.

19. Barco PP, Crosson B, Bolesta MM, Werts D, Stout R. Training awareness and compensation in postacute head injury rehabilitation. In: Kreutzer JS, Wheman PH, eds. Cognitive Rehabilitation for Persons With Traumatic Brain Injury: A functional Approach. Baltimore, MD: Paul H. Brookes; 1991:129-146.

20. Abreu BC, Seale G, Scheibel RS, Huddleston N, Zhang L, Ottenbacher KJ. Levels of self-awareness after acute brain injury: how patients' and rehabilitation specialists' perceptions compare. Arch Phys Med Rehabil. 2001;82:49-56.

21. Toglia J, Kirk U. Understanding awareness deficits following brain injury. Neurorehabilitation. 2000;15:57-70.

22. Dirette D. The development of awareness and the use of compensatory strategies for cognitive deficits. Brain Inj. 2002;16:861-871.

23. Andersson S, Gundersen PM, Finset A. Emotional activation during therapeutic interaction in traumatic brain injury: effect of apathy, self-awareness and implications for rehabilitation. Brain Inj. 1999;13:393-404.

24. Sherer M, Bergloff P, Boake C, High W, Levin E. The Awareness Questionnaire: factor structure and internal consistency. Brain Inj. 1998;12:63-68.

25. Boake C, Freelands JC, Ringholz GM, Nance ML. Awareness of memory loss after severe closed-head injury. Brain Inj. 1995;9:273283.

26. Clare L, Marková I, Verhey F, Kenny G. Awareness in dementia: a review of assessment methods and measures. Aging Ment Health. 2005;9:394-413.

27. Marková IS, Berrios GE. Approaches to the assessment of awareness: conceptual issues. Neuropsychol Rehabil. 2006;16:439-455.

28. Visser-Meily JMA, Post MWM, Riphagen II, Lindeman E. Measures used to assess burden among caregivers of stroke patients: a review. Clin Rehabil. 2004;18:601-623.

29. Marková IS, Clare L, Wang M, Romero B, Kenny G. Awareness in dementia: conceptual issues. Aging Ment Health. 2005;9:386-393.

30. Orfei MD, Caltagirone C, Spalletta G. The evaluation of anosognosia in stroke patients. Cerebrovasc Dis. 2009;27:280-289.

31. Havet-Thomassin V, Gardey AM, Aubin G, Le Gall D. Several factors to distinguish anosognosia from denial after a brain injury. Encephale. 2004;30:171-181.

32. Kammerer T, Singer L, Holderbach L. Anosognosia and transitory delusion of not-belonging concerning the right upper extremity after avulsion of brachial plexus and cranial trauma. Cab Psychiatr. 1957:12;13-17.

33. Santos CO, Caeiro L, Ferro JM, Albuquerque R, Figueira ML. Denial in the first days of acute stroke. J Neurol. 2006;253:10161023.

34. Narushima K, Moser DJ, Robinson RG. Correlation between denial of illness and executive function following stroke: a pilot study. J Neuropsychiatry Clini Neurosci. 2008;20:96-100.

35. Blonder LX, Ranseen JD. Awareness of deficit following right hemisphere stroke. Neuropsychiatr Neuropsychol Behav Neurol. 1994;7:260-266. 
36. Malia KB, Torode S, Powell GE. Insight and progress in rehabilitation after brain injury. Clin Rehabil. 1993;7:23-29.

37. De Bettignies BH, Mahurin RK, Pirozzolo FJ. Insight for impairment in independent living skills in Alzheimer's disease and multi-infarct dementia. J Clin Exp Neuropsych. 1990;12: 355-363.

38. Jorm AF, Christensen H, Henderson AS, Korten AE, MacKinnon AJ, Scott R. Complaints of cognitive decline in the elderly: a comparison of reports buy subjects and informants in a community survey. Psychol Med. 1994;24:365-374.

39. Sherer M, Hart T, Nick TG. Measurement of impaired selfawareness after traumatic brain injury: a comparison of the $\mathrm{Pa}$ tient Competency Rating Scale and the Awareness Questionnaire. Brain Inj. 2003;17:25-37.

40. Sohlberg M, Mateer C. Cognitive Rehabilitation: An Integrative Neuropsychological Approach. New York, NY: The Guilford Press; 2001.

41. Fleming J, Strong J, Ashton R. Cluster analysis of self-awareness levels in adults with traumatic brain injury and relationship to outcome. J Head Trauma Rehabil. 1998;13:39-51.

42. Gasquoine PG, Gibbons TA. Lack of awareness of impairment in institutionalized, severely and chronically disabled survivors of traumatic brain injury: a preliminary investigation. J Head Trauma Rehabil. 1994;9:16-24.

43. Martin-Scull R, Nilsen R. Evaluating awareness-a rating scale and its uses. Int J Cogn Tech. 2002;7:31-37.

44. Aybek S, Carota A, Ghika-Schmid F et al. Emotional behavior in acute stroke: the Lausanne emotion in stroke study. Cogn Behav Neurol. 2005;18:37-44.

45. Barrash J, Tranel D, Anderson SW. Acquired personality disturbances associated with bilateral damage to the ventromedial prefrontal region. Dev Neuropsychol. 2000;18:355-381.

46. Bohac DL, Malec JF, Moessner AM. Factor analysis of the MayoPortland Adaptability Inventory: structure and validity. Brain Inj. 1997;11:469-482.

47. Chervinsky AB, Ommaya AK, deJonge M, Spector J, Schwab K, Salazar AM. Motivation for traumatic brain injury rehabilitation questionnaire (MOT-Q): reliability, factor analysis, and relationship to MMPI-2 variables. Arch Clin Neuropsychol. 1998;13:433446.

48. Kolitz BP, Vanderploeg RD, Curtiss G. Development of the Key Behaviors Change Inventory: a traumatic brain injury behavioral outcome assessment instrument. Arch Phys Med Rehabil. 2003;84:277-284.

49. Prigatano GP, Borgaro S, Baker J, Wethe J. Awareness and distress after traumatic brain injury: a relative's perspective. J Head Trauma Rehabil. 2005;20:359-367.

50. Coetzer BR, du Toit PL. Impaired awareness following brain injury and its relationship to placement and employment outcome. $J$ Cogn Rehabil. 2002;20:20-24.

51. Hart T, Whyte J, Kim J, Vaccaro M. Executive function and self-awareness of 'real-world' behavior and attention deficits fol- lowing traumatic brain injury. J Head Trauma Rehabil. 2005;20: 333-347.

52. O’Keeffe FM, Dockree PM, Moloney P, Carton S, Robertson IH. Awareness of deficits in traumatic brain injury: a multidimensional approach to assessing metacognitive knowledge and onlineawareness. J Int Neuropsychol Soc. 2007;13:38-49.

53. Malec JF, Machulda MM, Moessner AM. Differing problem perceptions of staff, survivors, and significant others after brain injury. J Head Trauma Rehabil. 1997;12:1-13.

54. Newman AC, Garmoe W, Beatty P, Ziccardi M. Self-awareness of traumatically brain injured patients in the acute inpatient rehabilitation setting. Brain Inj. 2000;14:333-344.

55. Goverover Y. Categorization, deductive reasoning, and selfawarness: association with everyday competence in persons with acute brain injury. J Cin Exp Neuropsych. 2004;26:737749 .

56. Hartman-Maeir A, Soroker N, Oman SD, Katz N. Awareness of disabilities in stroke rehabilitation: a clinical trial. Disabil Rehabil. 2003;25:35-44.

57. Appelros P, Karlsson GM, Seiger A, Nydevik I. Neglect and anosognosia after first-ever stroke: incidence and relationship to disability. J Rehabil Med. 2002;34:215-220.

58. Bisiach E, Vallar G, Perani D, Papagno C. Unawareness of disease following lesions of the right hemisphere: anosognosia for hemiplegia and anosognosia for hemianopia. Neuropsychologia. 1986;24:471-482.

59. Cocchini G, Beschin N, Cameron A, Fotopoulou A, Della Sala S. Anosognosia for motor impairment following left brain damage. Neuropsychology. 2009;23:223-230.

60. McDonald S, Flanagan S, Rollins J, Kinch J. TASIT: a new clinical tool for assessing social perception after traumatic brain injury. $J$ Head Trauma Rehabil. 2003;18:219-238.

61. Langer KG, Samuels MC. Unawareness of disability in CVA: a comparison study with musculoskeletal patients. Cogn Behav Neurol. 2008;21:206-213.

62. Prigatano GP, Klonoff PS. A clinician's rating scale for evaluating impaired self-awareness and denial of disability after brain injury. Clin Neuropsychol. 1998;12:56-67.

63. Ownsworth T, McFarland K, Young R. Development and standardization of the Self-regulation Skills Interview (SRSI): a new clinical assessment tool for acquired brain injury. Clin Neuropsychol. 2000;14:76-92.

64. Anderson SW, Tranel D. Awareness of disease states following cerebral infarction, dementia, and head trauma: standardized assessment. Clin Neuropsychol. 1989;3:327-339.

65. Tham K, Ginsburg E, Fisher AG, Tegnér R. Training to improve awareness of disabilities in clients with unilateral neglect. $\mathrm{AmJ}$ Occup Ther. 2001;55:46-54.

66. Prigatano GP, Altman IM, O’Brien KP. Behavioral limitations that traumatic-brain-injured patients tend to underestimate. Clin Neuropsychol. 1990;4:163-176. 


\section{Appendix 1 Details of literature search "Measurements of awareness of deficits"}

\begin{tabular}{|c|c|}
\hline Database & Search \\
\hline PubMed & $\begin{array}{l}\text { ("Stroke"[MeSH Major Topic] OR "brain injuries" [MeSH Major Topic]) AND ("awareness" [MeSH } \\
\text { Major Topic] OR "unawareness"[title/abstract] OR "self-awareness"[title/abstract] OR } \\
\text { "insight" [title/abstract] OR "anosognosia"[title/abstract] OR "denial"[title/abstract]) }\end{array}$ \\
\hline Psyclnfo & $\begin{array}{l}\text { SET 1: MM "Cerebrovascular Accidents" } \\
\text { SET 2: MM "Brain Damage" OR MM "Traumatic Brain Injury" or MM "Brain Concussion" } \\
\text { SET 3: SET } 1 \text { or SET } 2 \\
\text { SET 4: AB awareness OR unawareness OR self-awareness OR insight OR anosognosia OR denial } \\
\text { RESULT SET: S3 AND S4 (Limits: Age groups: Adulthood (18yrs \& older); Population group: Human) }\end{array}$ \\
\hline EMBASE & $\begin{array}{l}\text { SET 1: *brain injury/ } \\
\text { SET 2: *cerebrovascular disease/ } \\
\text { SET 3: SET } 1 \text { OR SET } 2 \\
\text { SET 4: (awareness or unawareness or self-awareness or insight or anosognosia or denial).ab. } \\
\text { RESULT SET: SET } 3 \text { AND SET } 4\end{array}$ \\
\hline
\end{tabular}

\section{Appendix 2 Details of literature search into psychometric properties of the selected measurements}

\begin{tabular}{|c|c|}
\hline Database & Search \\
\hline PubMed & $\begin{array}{l}\text { ("SADI" [title/abstract] OR "Self-Regulation Skills Interview" [title/abstract] OR } \\
\text { "SRSI" [title/abstract] OR "Patient Competency Rating Scale" [title/abstract] OR } \\
\text { "PCRS" [title/abstract] OR "Awareness Questionnaire"[title/abstract] OR } \\
\text { "AQ" [title/abstract] OR "Clinician Rating Scale "[title/abstract] AND } \\
\text { ("Psychometrics" [MeSH] OR "responsiveness" [title/abstract] OR "consistency" [title/abstract] OR } \\
\text { "valid"[title/abstract] OR "validity" [title/abstract] OR "validation" [title/abstract] OR } \\
\text { "reliable" [title/abstract] OR "reliability"[title/abstract] } \\
\text { OR "Sensitivity and Specificity" [Mesh] OR "feasible"[title/abstract] OR "feasibility" [title/abstract] OR } \\
\text { "evaluation" [title/abstract] OR "characteristic*" [title/abstract]) } \\
\text { Limits: Humans, English, French, German, Dutch, Adult: 19-44 years } \\
\text { Error no results: "Self-Awareness of Deficits Interview"; "Awareness Interview-Adapted" }\end{array}$ \\
\hline Psyclnfo & $\begin{array}{l}\text { AB ("Self-Awareness of Deficits Interview" OR "SADI" OR "Self-Regulation Skills Interview" OR } \\
\text { "SRSI" OR "Awareness Interview-Adapted" OR "Patient Competency Rating Scale" OR "PCRS" } \\
\text { OR "Awareness Questionnaire" OR "AQ" OR "Clinicians Rating Scale for Evaluating Impaired } \\
\text { Self-Awareness") and AB (Psychometrics OR responsiveness OR consistency OR valid OR validity } \\
\text { OR validation OR reliable OR reliability OR Sensitivity OR Specificity OR feasible OR feasibility OR } \\
\text { evaluation OR characteristics) } \\
\text { Limits: Age Groups: Adulthood (18 yrs \& older); Population Group: Human }\end{array}$ \\
\hline EMBASE & $\begin{array}{l}\text { SET 1: ((Self-Awareness of Deficits Interview OR SADI) AND (psychometrics or responsiveness or } \\
\text { consistency or valid or validity or validation or reliable or reliability or Sensitivity or Specificity or } \\
\text { feasible or feasibility or evaluation or characteristics)).ab. } \\
\text { SET 2: ((Self-Regulation Skills Interview OR SRSI) AND (as SET 1)).ab. } \\
\text { SET 3: Awareness Interview-Adapted AND (as in SET 1).ab. } \\
\text { SET 4: ((Patient Competency Rating Scale OR PCRS) AND (as in SET 1)).ab. } \\
\text { SET 5: ((Awareness Questionnaire OR AQ) AND (as in SET 1)).ab. } \\
\text { SET 6: Clinician Rating Scale AND (as in SET 1).ab. } \\
\text { RESULT SET: S1 AND S2 AND S3 AND S4 AND S5 AND S6 }\end{array}$ \\
\hline
\end{tabular}

